\title{
Seismic risk assessment of Trani's Cathedral bell tower in Apulia, Italy
}

\author{
Mariella Diaferio $^{1} \cdot$ Dora Foti $^{1}$
}

Received: 18 October 2016/ Accepted: 8 June 2017/Published online: 14 June 2017

(c) The Author(s) 2017. This article is an open access publication

\begin{abstract}
The present paper deals with the evaluation of the seismic vulnerability of slender historical buildings; these structures, in fact, may manifest a high risk with respect to seismic actions as usually they have been designed to resist to gravitational loads only, and are characterized by a high flexibility. To evaluate this behavior, the bell tower of the Trani's Cathedral is investigated. The tower is $57 \mathrm{~m}$ tall and is characterized by an unusual building typology, i.e., the walls are composed of a concrete core coupled with external masonry stones. The dynamic parameters and the mechanical properties of the tower have been evaluated on the basis of an extensive experimental campaign that made use of ambient vibration tests and ground penetrating radar tests. Such data have been utilized to calibrate a numerical model of the examined tower. A linear static analysis, a dynamic analysis and a nonlinear static analysis have been carried out on such model to evaluate the displacement capacity of the tower and the seismic risk assessment in accordance with the Italian guidelines.
\end{abstract}

Keywords Nonlinear static analysis - Historical slender building - Vulnerability analysis · Finite element model . Concrete $\cdot$ Masonry materials

Mariella Diaferio

mariella.diaferio@poliba.it

1 Department Sciences of Civil Engineering and Architecture, Technical University of Bari, Via Orabona, 4, 70125 Bari, Italy

\section{Introduction}

In the last decade, the occurrence of damages and cracking on architectural heritage buildings due to seismic events and/or overloading, has stimulated research on masonry structures to define procedures able to protect such structures.

The protection of the architectural heritage against seismic events has become a strategic point for the territorial planning. This is especially required for all those countries that possess a wide and rich historical patrimony and which, on the other hand, are characterized by a high seismic risk, such as Italy. In this field, two different aspects have been studied by the researchers: the technical solutions for the protection of such structures (Modena et al. 2002; Osmancikli et al. 2012; Valluzzi et al. 2005; Lourenco 2005), and the problems connected with the definition of a model able to predict the structural response (D'Ambrisi et al. 2012; Diaferio et al. 2014a, 2016; Foti et al. 2015; Russo et al. 2010).

Due to an un-normalized constructive process, in fact, the Italian heritage includes a wide range of different typologies of masonry buildings that have not been designed to resist to the horizontal actions as those due to earthquakes. Among these construction typologies, the ones characterized by a high flexibility are particularly vulnerable to the seismic events, as they may show large amplitude oscillations incompatible with the mechanical properties of their structural elements (Ahmadi et al. 2014; Bartoli et al. 2013; Diaferio et al. 2014b; Foti 2014, 2015; Gentile and Saisi 2007; Tomaszewska and Szymczak 2012). A widespread typology is the bell tower, in particular, here the bell tower of the Trani's (Apulia, Italy) Cathedral is considered. As a consequence of the interventions done during the years, the tower is actually 
characterized by walls whose core is realized in concrete while the external facades are made with the original Trani stones.

Moreover, the examined structure, due to its slenderness, may be vulnerable to lateral loads, and consequently an accurate analysis is required.

The present paper deals with the definition and development of a numerical model of the bell tower and with its analysis for the evaluation of the seismic performances of this historical masonry tower. Unfortunately, all the necessary information were not available due to the lack of documents. In addition, the mechanical properties of the structural materials are unknown, because the structure is subjected to degradation phenomena and cracking. Another element of uncertainty is represented by the interaction with the surrounding Cathedral, and the presence of inhomogeneities, etc. The aforementioned problems commonly occur during the evaluation of the vulnerability of a historical building, therefore the examined case may be representative of a class of buildings.

In these cases, the approach may be oriented to the implementation of a wide experimental campaign that by means of ground penetrating radar tests, thermografy, etc. (Binda et al. 1998, 2005; Diaferio et al. 2015b), may give information regarding the local properties of the structure. Numerous procedures have been proposed for the evaluation of the mechanical properties of the structural materials and the mapping of the holes or the construction details that can be adopted also in the cases in which retrofitting interventions have been done (D'Ambrisi et al. 2012; Modena et al. 2002; Osmancikli et al. 2012). Nevertheless, as the dimensions of the examined structure increase, the possibility of evaluating all the required information for the definition of a numerical model-on which dynamic analysis could be performed-becomes cumbersome and other approaches have to be implemented.

In this field, the dynamic tests, the subsequent structural identification and the updating of a numerical model of the structure to match the experimental results (Diaferio et al. 2015c; Gentile and Saisi 2013; Ivorra and Pallares 2006; Ivorra et al. 2016; Ramos et al. 2010) is the most widely diffused approach. In fact, even if this approach gives information regarding the local properties of the structure less accurate than the ones supplied by the procedures in (Binda et al. 1998, 2005; Diaferio et al. 2015a, b, c), on the other hand, it is able to give a detailed description of the global behavior of the structure that can be used for judging its safety level and be a useful tool for decision makers.

The use of dynamic tests, modal identification and subsequent updating of a numerical model of the structure has been also proposed in the literature for the estimation of the constraint conditions due to the interaction between the examined tower and the surroundings structures (Diaferio et al. 2016; Gentile and Saisi 2007).

Due to the complexity of Trani's bell tower, with walls made by coupled concrete and masonry materials and unknown connections with the contiguous Cathedral, the numerical model has been validated by means of a comparison with the results of a wide experimental campaign. In situ tests have been conducted both by "local" nondestructive methods, such as ground penetrating radar (GPR) tests, and "global" methods, such as dynamic tests performed in operational conditions.

The main purpose of the present paper is to investigate the seismic vulnerability of the tower by means of such reliable numerical model experimentally validated, in accordance with the Italian guidelines for seismic risk assessment and mitigation of cultural heritage.

\section{Trani's Cathedral bell tower}

Trani's Cathedral is one of the most significant structures in Apulian Romanesque style (Fig. 1); its construction began at the end of the eleventh century and ended in 1143 . The bell tower was built starting in 1240 and ended in the second half of 1300 .

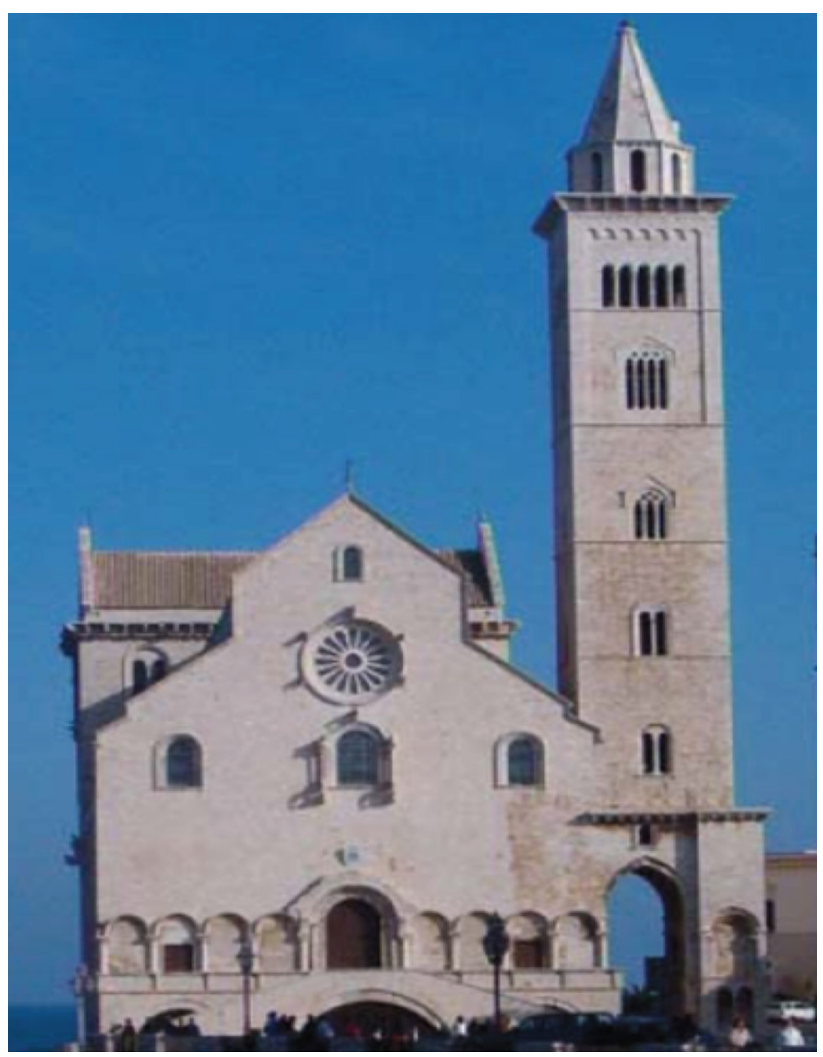

Fig. 1 Trani's Cathedral and its bell tower 
Trani's Cathedral bell tower has a square transversal section, above the pointed arch that connects the tower to the Cathedral. Up to the arch, at a level of about $14.30 \mathrm{~m}$, there is a rigid floor in correspondence of the opening that connects the bell tower to the church.

From this level upwards, the square plan section with $7.50 \mathrm{~m}$ side remains constant for five floors up to the quote of about $47.6 \mathrm{~m}$. At the top, the tower section becomes octagonal with a side of about $2.3 \mathrm{~m}$.

The octagonal section remains constant up to the quote of about $51 \mathrm{~m}$ up to which the dome emerges.

The total height of the tower is $57 \mathrm{~m}$, the walls thickness in correspondence of the square plan section is about $1.40 \mathrm{~m}$.

The first two floors show on each façade round arched mullioned windows, while at the third and fourth levels, respectively, three- and four-light windows are present, while the upper floor (fifth level) is characterized by fivelight windows.

During the years, the tower has been subjected to numerous structural interventions; in fact, since from 1700 the tower has exhibited static problems. However, the most severe intervention has been performed in the 1950, when the tower was completely disassembled, and a concrete core was built for reducing its oscillations. The tufa masonry (Trani stone) blocks were reassembled on the concrete core in the same original position.

\section{The finite element model}

To define a refined three-dimensional finite element (FE) model of the examined bell tower, an accurate analysis of the available historical documents and drawings has been executed. Nevertheless, due to the lack of information regarding the mechanical properties of the structural materials, the dimensions of the concrete core, and the constraint conditions due to the connection with the Cathedral, an extensive experimental campaign has been performed. In detail, a preliminary geometric survey and ground penetrating radar (GPR) tests have been conducted at each level of the tower.

In detail, the system IDS HI-MOD with a high frequency transmitter and receiver antenna $(2 \mathrm{GHz})$ has been used, and the investigation has been considered $1 \mathrm{~m}$ of depth of the walls. Several acquisitions have been carried out at different levels of the tower and moving the radar following a line on the wall. The results demonstrate the presence in the core of the walls of material less coherent than the external surface, the latter one, whose thickness is about $25 \mathrm{~cm}$, is characterized by regular and squared blocks of good quality and good consistency.
Then, dynamic tests in operational conditions have been performed by means of a monitoring system, consisting into 28 PCB (Model 393B31) uniaxial piezoelectric accelerometers connected to four digital acquisition systems connected to a laptop by an ethernet cable. The accelerometers were placed on four different levels of the tower. Eleven consecutive tests were conducted on the tower; each test had duration of $10 \mathrm{~min}$ with a sampling frequency of $1024 \mathrm{~Hz}$, which has been subsequently decimated by a factor equal to 4 to have a frequency of $256 \mathrm{~Hz}$. The acquired data have been analyzed by means of two operational modal analysis techniques (Diaferio et al. 2015b): one that operates in the frequency domain and the other one in the time domain. Table 1 shows the identified natural frequencies that have been evaluated as mean values of the identification results obtained analyzing all the acquired data during the numerous dynamic tests performed on the bell tower.

Based on the available information a three-dimensional FE model has been defined by means of Straus Software package (Straus7). The tower has been modeled with 8-nodes 4093 plate elements (QUAD8) that can better describe the behavior of thick plates like the ones here considered (Fig. 2); such shell element is a quadrilateral element which assumes as nodes the four corners and other four extra nodes along the four edges. The tower has been considered fully fixed at the base, while its connection with the adjacent Cathedral has been modeled by means of springs. Moreover, the stairs and the bells have been neglected into the FE model as their values are not significant respect to the structural mass. The thickness of the shell elements has been defined in accordance with the available drawings.

The walls have been modeled with a homogeneous material. In fact, as confirmed by GPR tests, there is a perfect connection between the external Trani's stones and the concrete core. Consequently, the walls have been modeled with a uniform material whose mechanical properties (i.e., density and elastic modulus) have been obtained by weighted averaging of the contributions of the stones and the concrete with respect to the thickness

Table 1 Results of the modal identification: estimated frequencies for each natural mode

\begin{tabular}{ll}
\hline \# Mode & Frequency mean value $(\mathrm{Hz})$ \\
\hline 1 & 2.04 \\
2 & 2.26 \\
3 & 7.03 \\
4 & 7.60 \\
5 & 9.16 \\
\hline
\end{tabular}


Fig. 2 FE model of Trani's Cathedral bell tower

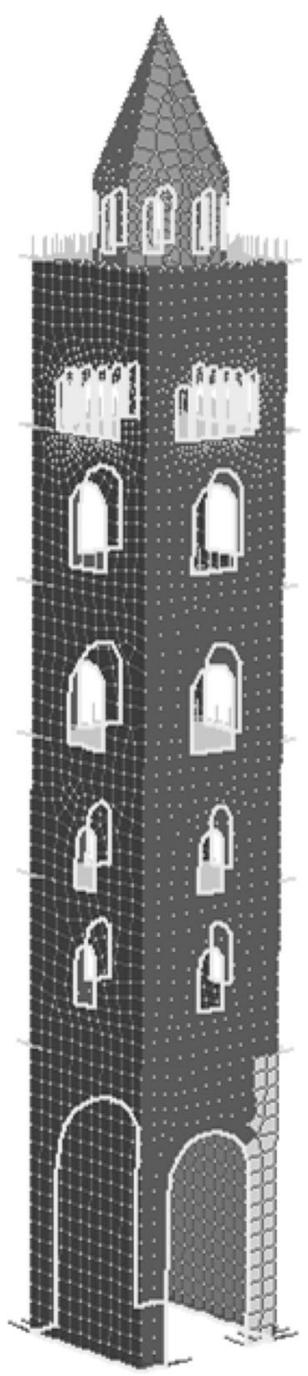

Table 2 Comparison between experimental and numerical frequencies for each one of the first five modes

\begin{tabular}{lll}
\hline \# Mode & Experimental frequency $(\mathrm{Hz})$ & Numerical frequency $(\mathrm{Hz})$ \\
\hline 1 & 2.04 & 2.04 \\
2 & 2.26 & 2.25 \\
3 & 7.03 & 7.761 \\
4 & 7.60 & 7.884 \\
5 & 9.16 & 9.136 \\
\hline
\end{tabular}

(a)

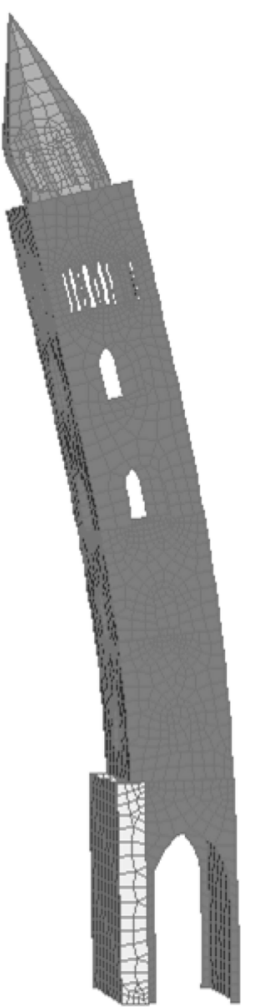

(b)

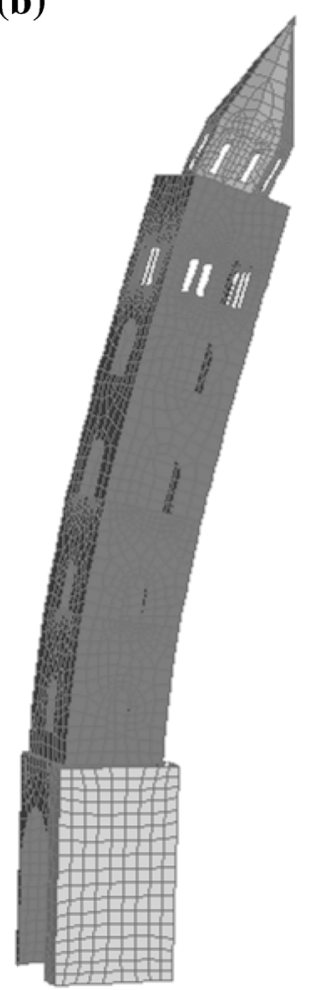

Fig. 3 a The first mode shape $f_{1}=2.04 \mathrm{~Hz} ; \quad$ b the second mode shape $f_{2}=2.25 \mathrm{~Hz}$

\section{The seismic hazard}

Trani's area is a seismic prone zone. According to the seismic Italian code (NTC 2008; DPCM 2011), the site is characterized by the hazard curve in Fig. 4, where the PGA at the bedrock $a_{\mathrm{g}}$ is plotted varying the return period $T_{\mathrm{R}}$. The PGA at the bedrock with a 475 years return period is equal to $a_{\mathrm{g}}=0.145 \mathrm{~g}$. For the site effect, a rock mass has been assumed for the subsoil condition and a flat land for the topographic condition; on such basis an amplification factor $S=1.0$ has been adopted in accordance with the Italian building code (NTC 2008; DPCM 2011).

The behavior factor has been assumed equal to 2.25 that is the value suggested by the Italian building code (NTC 
Fig. 4 Seismic hazard curve at the bell tower site

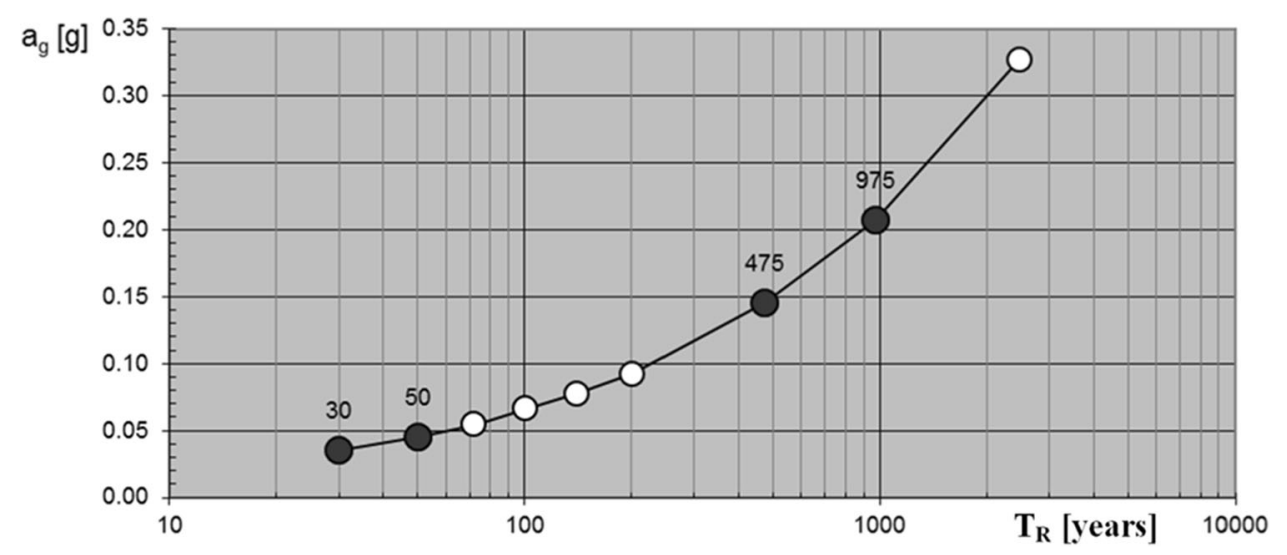

08) for towers irregular in elevation like in the case here considered, which is characterized by the presence of the Cathedral only on one side of the tower. In Fig. 5. the elastic response spectrum $S_{\mathrm{e}}$ and the design response spectrum related to the horizontal direction $S_{\mathrm{d}}$ are shown for the life safe limit state.

\section{Static and seismic analysis}

A preliminary linear static analysis has been performed on the FE model of the tower, assuming the tower fully fixed at the base and by simulating the interaction with the adjacent Cathedral by means of springs, as aforementioned. The tower has been considered subjected to self-weights and live loads (the latter equal to $5 \mathrm{kN} / \mathrm{m}^{2}$ ), the evaluated normal stresses are shown in Fig. 6. It can be observed that the values are compatible with the ordinary resistances of concrete and masonry materials $\left(\cong 25 \mathrm{~N} / \mathrm{mm}^{2}\right)$.

Moreover, the model has been subjected to the design spectra in Fig. 5. The walls have been verified; in Fig. 7b an example of the performed analysis is shown for the wall at the first floor, the latter reported in Fig. 7a.

A nonlinear static analysis has been performed by adopting lateral forces distributed linearly along the height of the tower; in detail, the introduced forces are

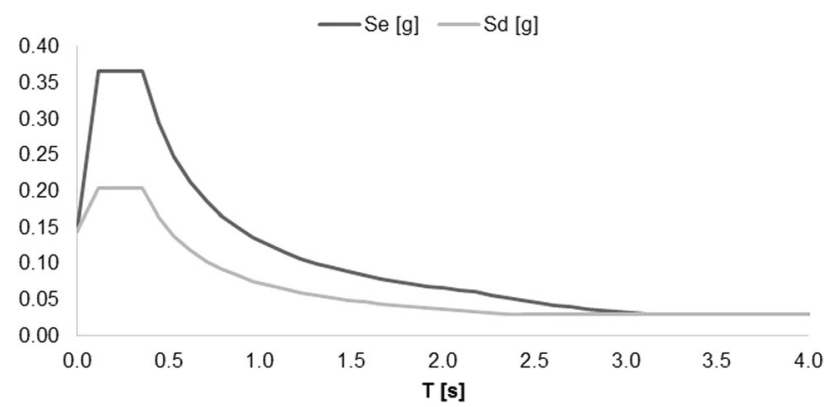

Fig. 5 Elastic and design response spectra for life safe limit state

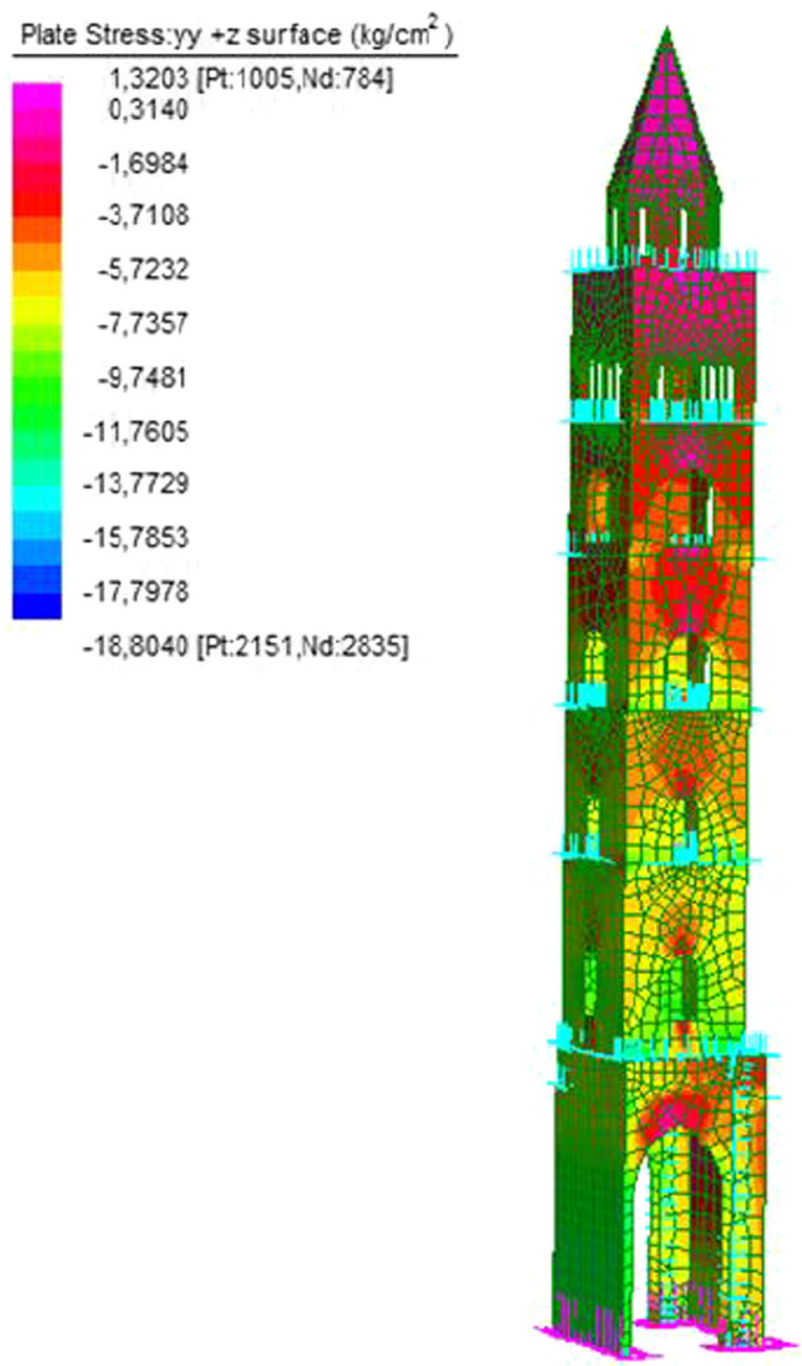

Fig. 6 Normal stress pattern due to static loads

proportional to the masses and to the displacements of the normalized first mode of the structure in the considered direction: 
Fig. 7 a In the black rectangular the considered wall; b normal force-moment domain, in blue the stress condition (a)

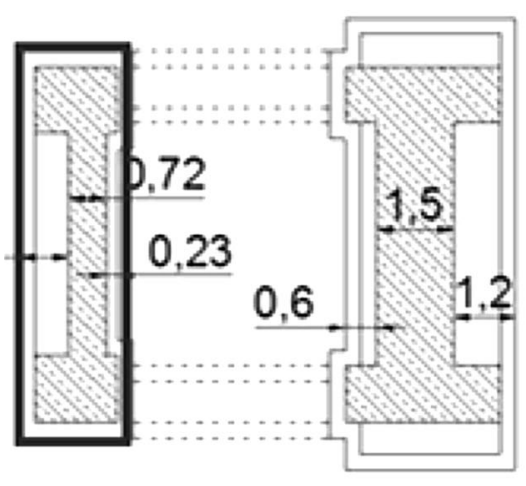

(b)

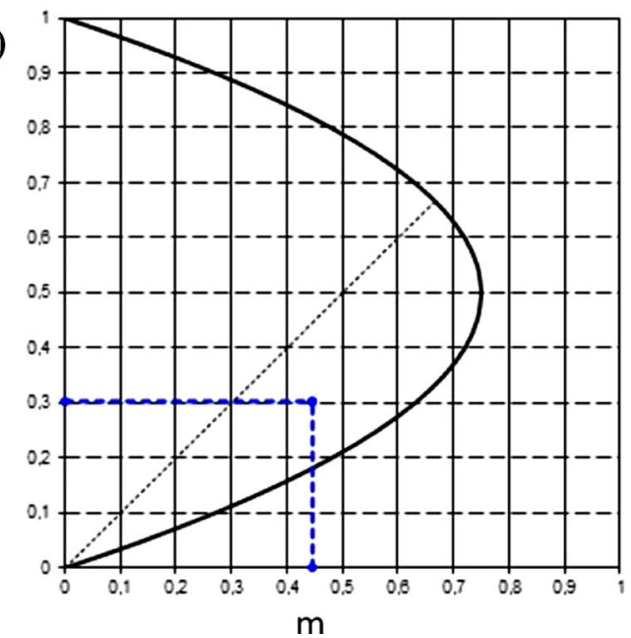

$F_{i}=\left(S_{d}\left(T_{1}\right) \frac{W \lambda}{g}\right) \frac{W_{i} z_{i}}{\sum_{j=1}^{n} W_{j} z_{j}}=F_{h} \frac{W_{i} z_{i}}{\sum_{j=1}^{n} W_{j} z_{j}}$,

where $W$ is the total mass, $W_{i}$ and $z_{i}$ are the mass and the height at the $i$ th level, $g$ is the gravity acceleration and $S_{\mathrm{d}}\left(T_{1}\right)$ is the design acceleration evaluated in accordance with the design response spectrum and referred to the first period of the tower, and $\lambda$ is the coefficient that depends on the geometrical characteristics of the structure. For the case here considered $F_{h}$ is equal to $2019 \mathrm{kN}$.

Figure 8 shows the stress-strain relationship that has been adopted for describing the nonlinear behavior of the structural material.

The pushover analysis has been carried out up to the collapse, which has been characterized taking into account different criteria to compare the results.

As a first step, the Rankine criterion (maximum stress) has been adopted as yield criterion.

Analyzing the distribution of the stress along the tower during the sequence of load increment, it can be verified that at the 12th step the maximum compressive strain is reached in correspondence of a load that is $20 \%$ greater than the load of life safe limit state (Fig. 9).

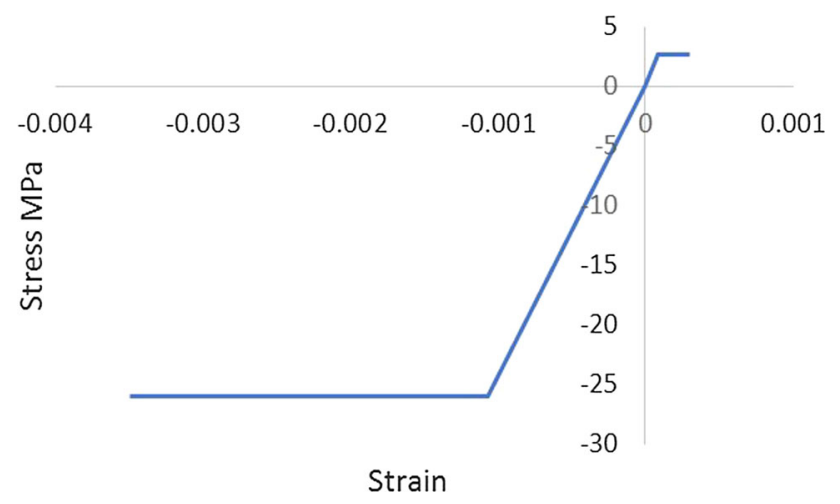

Fig. 8 Stress-strain relation of the structural material
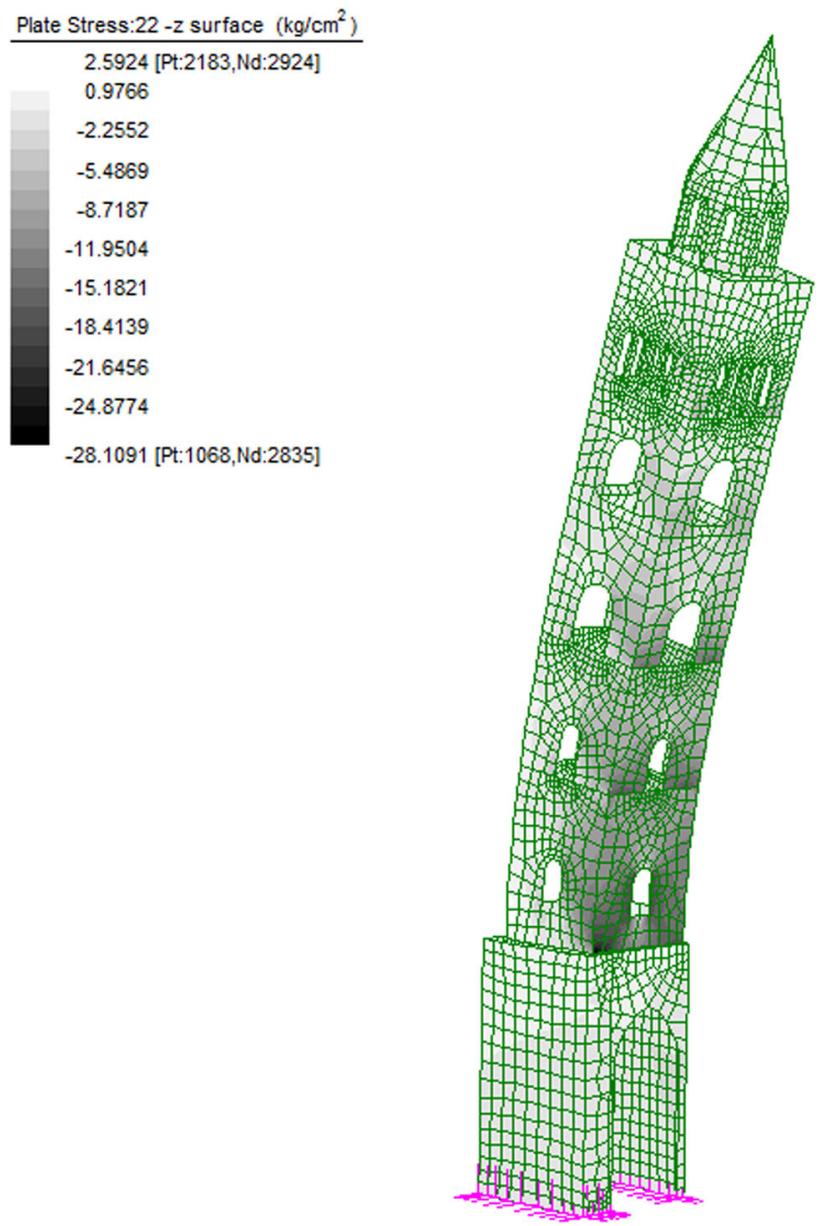

Fig. 9 Stress pattern of nonlinear static analysis (Rankine criterion)

Moreover, the maximum tensile stresses appear at the 8th step that is in correspondence of a load equal to $80 \%$ of the load for the life safe limit state (Fig. 10).

The nonlinear static analysis has been performed also adopting, as yield criterion, the Coulomb criterion: 

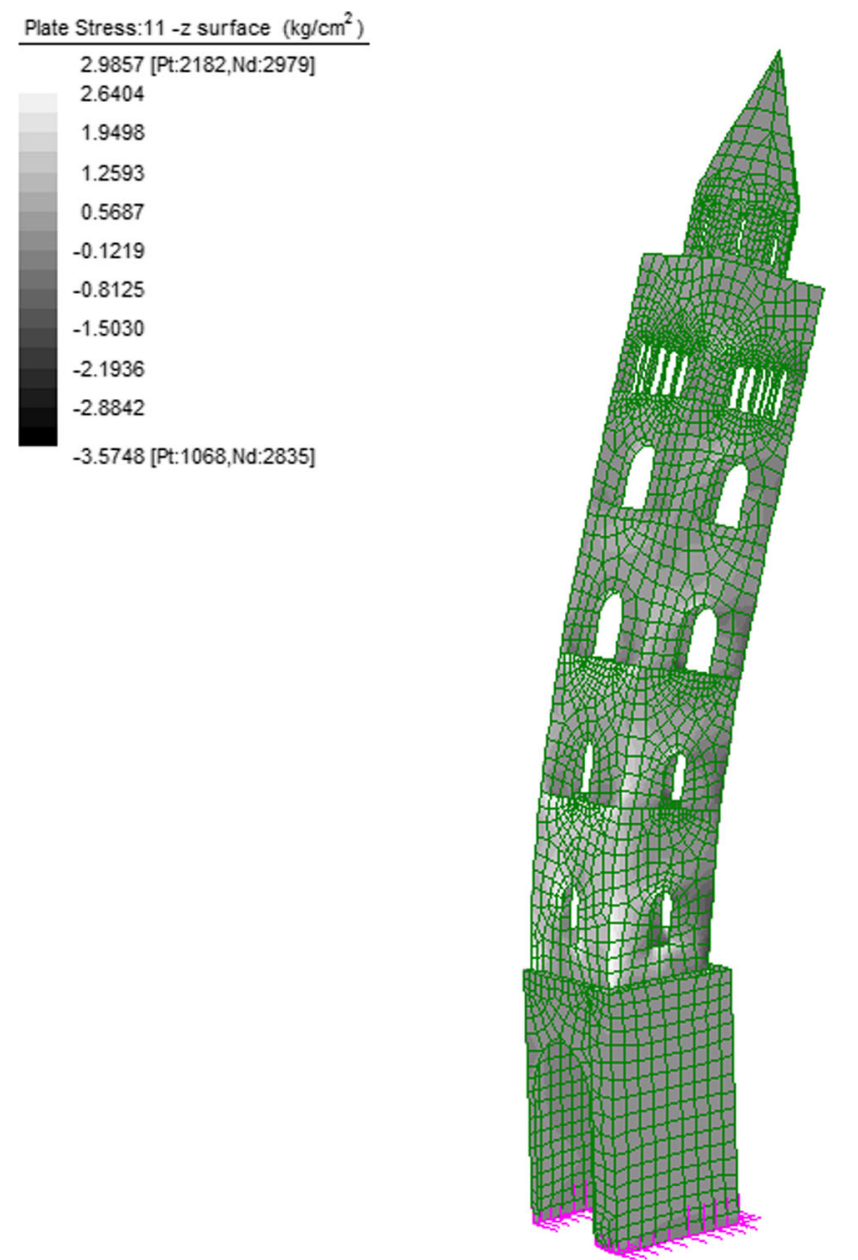

Fig. 10 Stress pattern of nonlinear static analysis (maximum tensile stress)

$\tau=c+\sigma \operatorname{tg}(\varphi)$

where $\tau$ is the shear stress, and it has been assumed $c=0.37, \sigma=0.64 \mathrm{MPa}$ and $\operatorname{tg}(\varphi)=0.4$. Thus, the limit value for the shear stress is equal to $0.29 \mathrm{MPa}$. Figure 11 shows the stress pattern of the tower the zones where the maximum shear stress compatible with the Coulomb criterion is achieved, can be observed.

Above three risk assessment criteria have been analyzed: Rankine criterion, maximum tensile stress and Coulomb criterion. To verify the actual safety level of the bell tower in the following, the three above mentioned criteria have been compared and the safest one has been adopted as risk assessment criteria.

In Fig. 12, the capacity curve (number of the load step increment vs. the maximum displacement of the center of mass of the upper level) of the examined bell tower is shown, and the displacement capacity, evaluated for each one of the aforementioned criteria, is plotted.
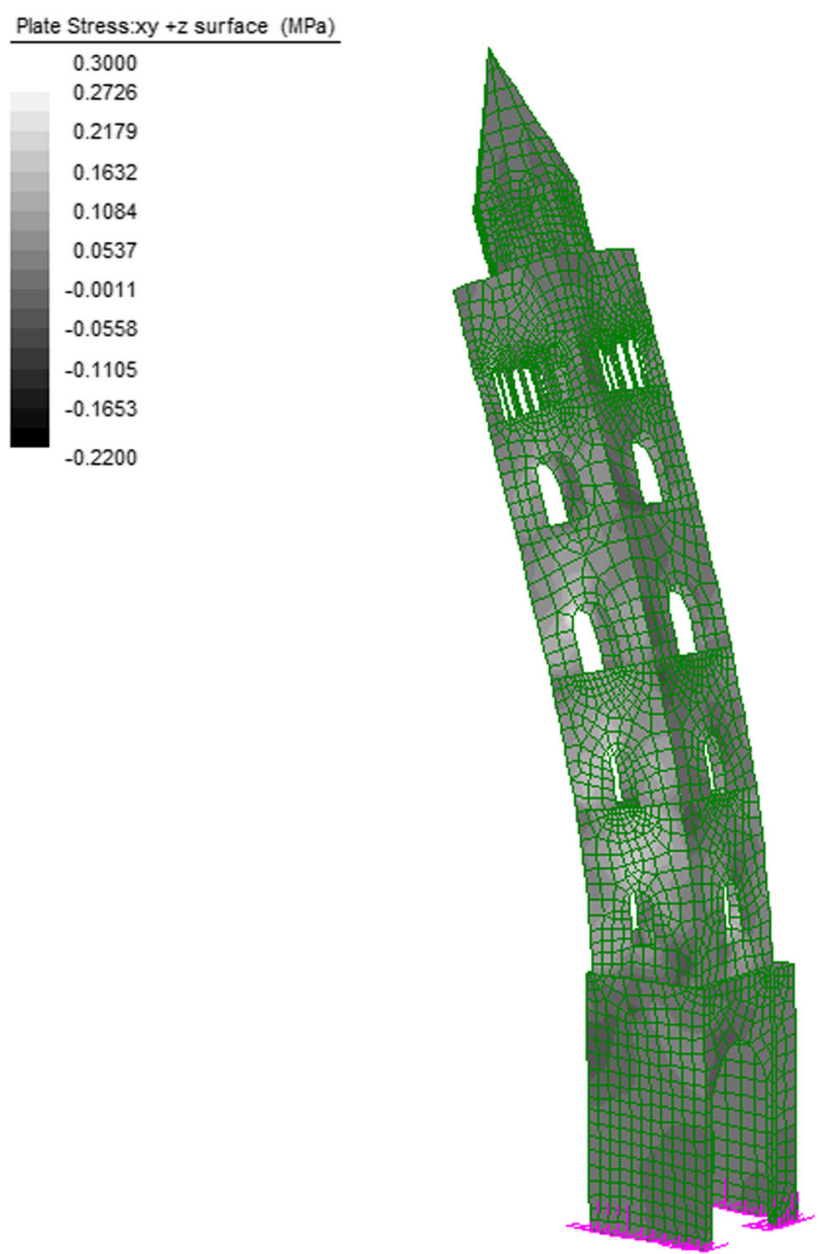

Fig. 11 Stress pattern of nonlinear static analysis (Coulomb criterion)

The maximum tensile stress criterion is the one that estimates the lower displacement capacity; consequently, it is the one adopted as risk assessment criteria.

The pushover curve has been managed to evaluate the curve of the equivalent Single Degree of Fredom (SDOF) system.

In accordance with the Italian building code (NTC 2008), the base shear force $F$ and the roof displacement $d$ obtained by the pushover analysis have to be converted into the corresponding modal force $F^{*}$ and displacement $d^{*}$ of the equivalent SDOF system, as follows:

$d^{*}=\frac{d}{\Gamma} \quad F^{*}=\frac{F}{\Gamma}$,

where $\Gamma$ is the modal participation factor.

On such basis the equivalent SDOF system has been defined in accordance with the Italian building code (NTC 2008; DPCM 2011). Figure 13 shows the comparison between the capacity curve of the tower and the bilinear 
Fig. 12 Capacity curve of the bell tower

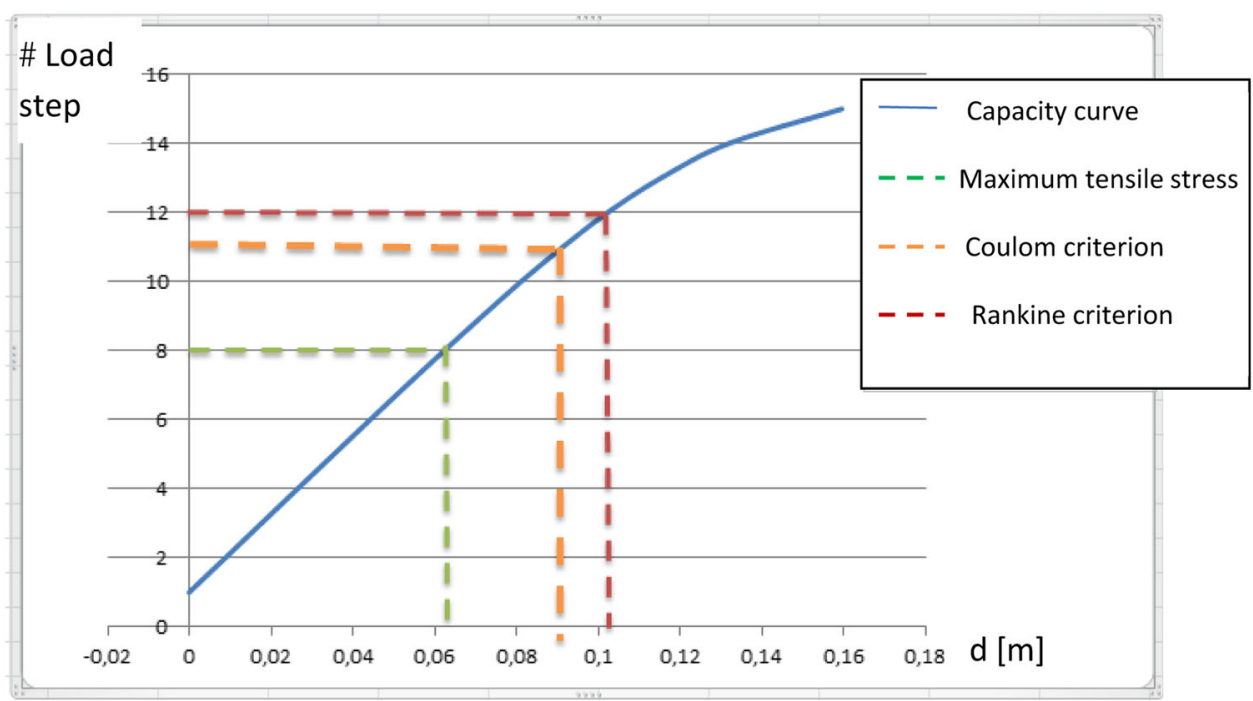

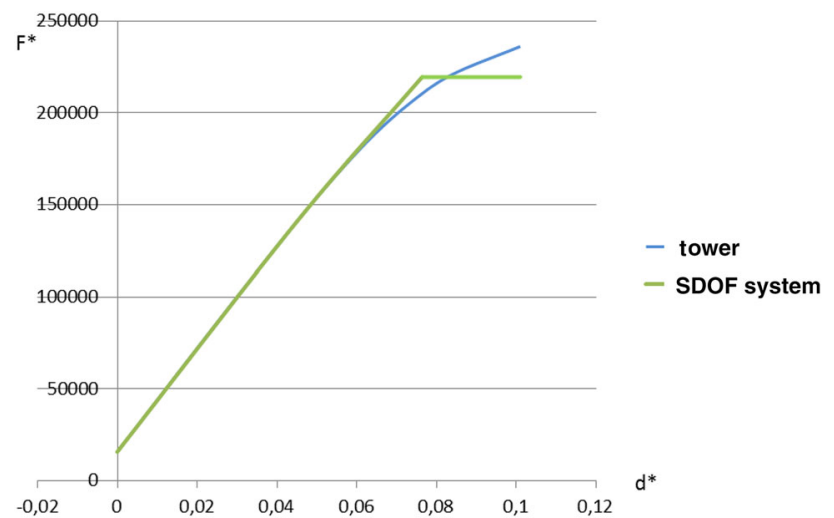

Fig. 13 Comparison between the capacity curve of the tower (blue line) and the bilinear curve of the equivalent SDOF system (green line)

curve of the equivalent SDOF system. The bilinear curve gives a behavior factor that is defined as the ratio between the maximum displacement and the yielding displacement equal to 1.34 , lower than the value suggested by the Italian code (NTC 08).

The period of the SDOF system $T^{*}$ is

$T^{*}=2 \pi \sqrt{\frac{m^{*}}{k^{*}}}$

where $m^{*}=\sum m_{i} \phi_{i}, m_{i}$ is the mass at the $i$ th floor level of the tower, $\phi_{i}$ is the $i$ th component of the first eigenvector, and $k^{*}$ is the elastic stiffness of the equivalent bilinear curve. In the present case study, it has been obtained $T^{*}=0.4 \mathrm{~s}$.

The seismic displacement demand evaluated in accordance with the Italian code is $0.4 \mathrm{~m}$, higher than the maximum displacement estimated by means of the pushover analysis.

\section{Conclusions}

A nonlinear pushover analysis procedure has been applied to study the seismic vulnerability and quantify the failure risk of the Trani Cathedral's bell tower, one of the most important heritage buildings in Apulian Romanesque style. The tower is constituted by walls composed by a concrete core and external layers made by Trani stone.

A three-dimensional finite element model of the tower has been defined on the basis of an extensive experimental campaign and validated by means of dynamic tests under ambient forces. Ground penetrating radar tests have been carried out too to get more information and to appropriately calibrate the 3D finite element model.

Three risk assessment criteria (Rankine criterion, maximum tensile criterion and Coulomb criterion) have been compared and the safest one has been adopted to evaluate the displacement capacity of the bell tower and its seismic vulnerability. Then the capacity curve of the examined structure has been evaluated considering the life safe limit state and analyzing the possible global collapse mechanisms.

The vulnerability analysis has shown that the seismic displacement demand, evaluated in accordance with the Italian Building Code for seismic hazard of Trani, is higher than the maximum displacement capacity obtained adopting the maximum tensile stress criterion.

Acknowledgements This work was supported by PRIN-MIUR 2015 research project entitled "Mitigating the impact of natural hazards on cultural heritage sites, structures and artefacts (MICHe)".

Open Access This article is distributed under the terms of the Creative Commons Attribution 4.0 International License (http://crea tivecommons.org/licenses/by/4.0/), which permits unrestricted use, 
distribution, and reproduction in any medium, provided you give appropriate credit to the original author(s) and the source, provide a link to the Creative Commons license, and indicate if changes were made.

\section{References}

Ahmadi G, Keshtkar R, Mavizchi M, Vetr MG (2014) Using seismic hazard assessment to study dynamic behavior of Gonbad-e Kāvus tower (the tallest brick tower in the world. Int J Adv Struct Eng (2014) 6:133-148. doi:10.1007/s40091-014-0071-4

Bartoli G, Betti M, Giordano S (2013) In situ static and dynamic investigations on the "Torre Grossa" masonry tower. Eng Struct 52:718-733

Binda L, Lenzi G, Saisi A (1998) NDE of masonry structures: use of radar tests for the characterization of stone masonries. NDT E Int 31(6):411-419

Binda L, Zanzi L, Lualdi M, Condoleo P (2005) The use of georadar to assess damage to a masonry bell tower in Cremona, Italy. NDT E Int 38:171-179

D’Ambrisi A, Mariani V, Mezzi M (2012) Seismic assessment of a historical masonry tower with nonlinear static and dynamic analyses tuned on ambient vibration tests. Eng Struct 36:210-219

Diaferio M, Foti D, Giannoccaro NI, Ivorra S (2014a) Optimal model through identified frequencies of a masonry building structure with wooden floors. Int J Mech 8(1):282-288

Diaferio M, Foti D, Giannocaro NI (2014b) Non-destructive characterization and identification of the modal parameters of an old masonry tower EESMS 2014-2014 IEEE Workshop on environmental, energy and structural monitoring systems, Proceedings, art. no. 6923265: 57-62

Diaferio M, Foti D, Gentile C, Giannoccaro NI, Saisi A (2015a) Dynamic testing of a historical slender building using accelerometers and radar. In: Proceedings 6th international operational modal analysis conference, IOMAC 2015; Abba Hotel Gijon; Spain; 12-14 May 2015

Diaferio M, Foti D, Giannoccaro NI (2015b) Identification of the modal properties of a squat historic tower for the tuning of a FE model. In: Proceedings 6th international operational modal analysis conference, IOMAC 2015; Abba Hotel Gijon; Spain; 12-14 May 2015

Diaferio M, Foti D, Giannoccaro NI (2015c) Identification of the modal properties of a building of the Greek heritage. Key Eng Mat 628:150-159. doi:10.4028/www.scientific.net/KEM.628. 150

Diaferio M, Foti D, Giannoccaro NI (2016) Modal parameters identification on environmental tests of an ancient tower and validation of its FE model. Int J Mech 10:80-89

DPCM (2011) Valutazione e riduzione del rischio sismico del patrimonio culturale con riferimento alle NTC 14 gennaio 2008. DPCM 9 febbraio 2011, G.U.R.I., Roma, Italy (in Italian)
Foti D (2014) Non-destructive techniques and monitoring for the evolutive damage detection of an ancient masonry structure. Key Eng Mater 628:168-177

Foti D (2015) A new experimental approach to the pushover analysis of masonry buildings. Comput Struct 147:165-171 (ISSN: 0045-7949)

Foti D, Diaferio M, Giannoccaro NI, Ivorra S (2015) Structural identification and numerical models for slender historical structures. In: Handbook of research on seismic assessment and rehabilitation of historic structures, ICI Global, Hershey p 674-703. ISBN: 9781466682863, doi: 10.4018/978-1-46668286-3.ch023

Gentile C, Saisi A (2007) Ambient vibration testing of historic masonry towers for structural identification and damage assessment. Constr Build Mater 21(6):1311-1321

Gentile C, Saisi A (2013) Operational modal testing of historic structures at different levels of excitation. Constr Build Mater 48:1273-1285

Ivorra S, Pallares FJ (2006) Dynamic investigations on a masonry bell tower. Eng Struct 28(5):660-667

Ivorra S, Brotóns V, Foti D, Diaferio M (2016) A preliminary approach of dynamic identification of slender buildings by neuronal networks. Int J Nonlinear Mech 80:183-189

Lourenco PB (2005) Assessment, diagnosis and strengthening of Outeiro Church, Portugal. Constr Build Mater 19(8):634-645

NTC (2008) Norme tecniche per le costruzioni. D.M. Ministero Infrastrutture e Trasporti 14 gennaio 2008, G.U.R.I., Roma, Italy

Modena C, Valluzzi MR, Tongini FR, Binda L (2002) Design choices and intervention techniques for repairing and strengthening of the Monza Cathedral bell tower. Constr Build Mater 16:385-395

Osmancikli G, Uçak S, Nur Turan F, Türker T, Bayraktar A (2012) Investigation of restoration effects on the dynamic characteristics of the Hagia Sophia bell tower by ambient vibration test. Constr Build Mater 29:564-572

Ramos L, Marques L, Lourenco P, De Roeck G, Campos-Costa A, Roque J (2010) Monitoring historical masonry structures with operational modal analysis: two case studies. Mech Syst Signal Process 24(5):1291-1305

Russo G, Bergamo O, Damiani L, Lugato D (2010) Experimental analysis of the "Saint Andrea" Masonry Bell Tower in Venice. A new method for the determination of Tower Global Young's Modulus E. Eng Struct 32:353-360

Straus7, G + D Computing Pty Limited, http://www.straus7.com

Tomaszewska A, Szymczak C (2012) Identification of the Vistula Mounting tower model using measured modal data. Eng Struct 42:342-348

Valluzzi MR, Binda L, Modena C (2005) Mechanical behaviour of historic masonry structures strengthened by bed joints structural repointing. Constr Build Mater 19:63-73 